\title{
Fluctuation of Extremely Cold and Warm Months in Bulgaria
}

\section{Nina Nikolova, Daniel Penev}

\begin{abstract}
The paper investigate analyze temporal and spatial changes in extremely cold and warm months in Bulgaria during the period 1961-2004. The relation between fluctuations of extreme months and teleconnection is study by North Atlantic Oscillation Indices (NAOl) and Eastern Atlantic pattern (EA). Cluster analysis is applied in order to analyze spatial changes in the occurrence of extreme temperature months for investigated meteorological stations.
\end{abstract}

Key words: extremely warm months, extremely cold months, cluster analysis.
Faculty of Geology and Geography, "St. Kliment Ohridski" University of Sofia, Tsar Osvoboditel Blvd. 15, 1504 Sofia, Bulgaria

\section{Introduction}

Study fluctuation of air temperature and especially temperature extremes is very important task due to increasing occurrence of extreme weather events during last decades. However there are a few research works on extreme values of monthly means of air temperatures in Bulgaria (Velev, 2003, Vekilska, 1973, Tishkov, 1963). Most of publications consider many-years fluctuation of monthly and annual temperatures (Velev 2002, Topliiski, 2002, Alexandrov et all, 2004). Knowledge about fluctuation of extreme values of monthly temperatures brings to better clarify longterm trends in temperature extremes and understand contemporary climate.

The objectives of present research are extreme values of monthly mean air temperature in Bulgaria. The aim is to analyze temporal and spatial changes in extremely cold and warm months.

\section{Data and Methods}

\section{Data}

The present analysis is based on the monthly data for air temperature from 20 meteorological stations in Bulgaria. The stations are representative of regions with different geographical and climatic conditions. The main investigated period is $1961-2004$ and the reference period is 1961-1991, determined by World Meteorological Organization as "contemporary climate". Data are taken from Meteorological yearbooks, Statistical yearbooks and Bulletins of Ministry of Environment and Water, Bulgaria. In order to give more information about chronological variation in extremely cold and warm months country averaged monthly temperature data are used. The country aggregation is based on the CRU TS 2.0 gridded data-set (http://www.cru. uea.ac.uk/ timm/, Mitchell et all., 2002).

The role of natural circulation mechanisms for occurrence of extreme monthly temperatures is clarified by using data for NAO indices (NAOI) (Jones et all., 1997, Osborn T., J., 2006 ) and East Atlantic (EA) pattern are also used in this research.

The NAO dictates climate variability from the eastern seaboard of the United States to Siberia and from the Arctic to the subtropical Atlantic. The NAO refers to a north-south oscillation in atmospheric mass with centers of action near Iceland and over the subtropical Atlantic from the Azores across the Iberian Peninsula. During the months December through March, for instance, the NAO accounts for more than one-third of the total variance in SLP over the North Atlantic. (Hurrell, 200o). Positive phases of the NAO are associated with below-average temperatures in Greenland and oftentimes across southern Europe and the Middle East.

The East Atlantic (EA) pattern is the second prominent mode of low-frequency variability over the North Atlantic, and appears as a leading mode in all months. The EA pattern is often interpreted as a "southward shifted" NAO pattern. The positive phase of the EA pattern is associated with above-average surface temperatures in Europe in all months (Barnston, A. G., and B. E. Livezey, 1987).

\section{Methods}

Extreme warm months are defined as a months whose mean air temperatures are higher (warmer) than 90\% percentiles of normal distribution in the reference period 1961-1990. As extreme cold month we consider the month with mean temperature lower (colder) than $10 \%$ of normal distribution. Extremely cold and warm months were determined for every of 20 stations during the period 1961-2004 and for area averaged time series for period 1900-2000. We consider number of station with at least one cold and one warm month during the year and number of station with three and more extremely months. This method has been applied for Individual teleconnection patterns: North Atlantic Oscillation and East Atlantic.

Spatial changes in occurrence of extremely temperatures are analyzed by cluster analysis. Application of this method gives a tool for classify meteorological stations according the occurrence of extremely cold and warm months over the territory of Bulgaria. We have applied complete linkage and Euclidean distances for the period 1961-2004.

The correlation analysis is applied in order to determine the role of atmospheric 


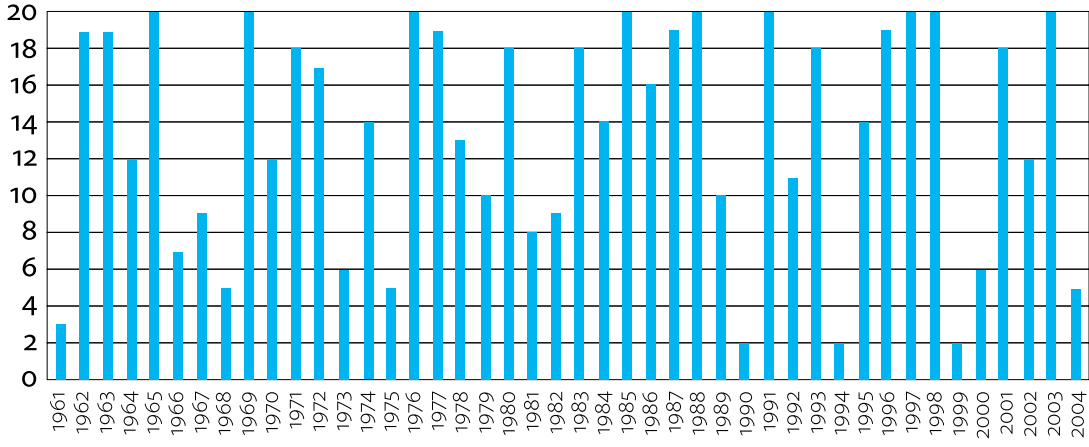

Figure 1 Number of stations with at least one extremely cold month

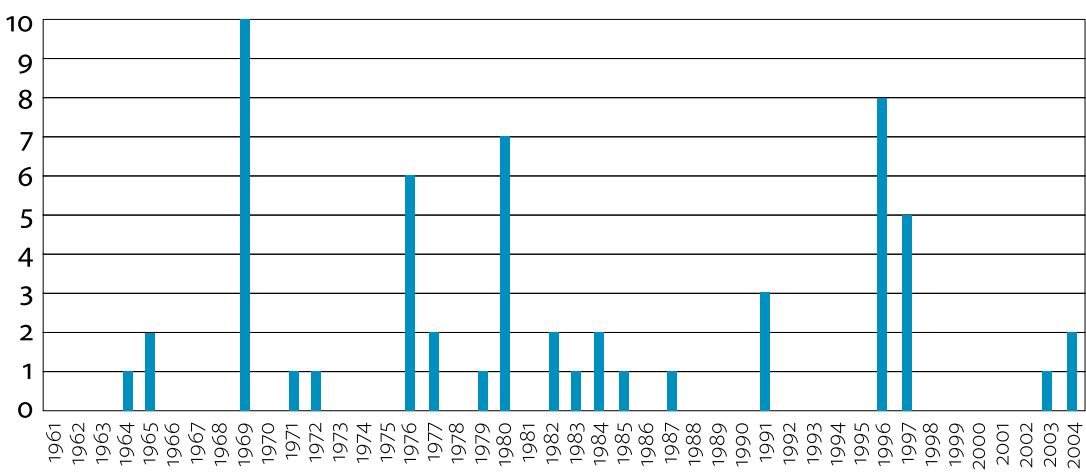

Figure 2 Number of stations with three and more extremely cold month

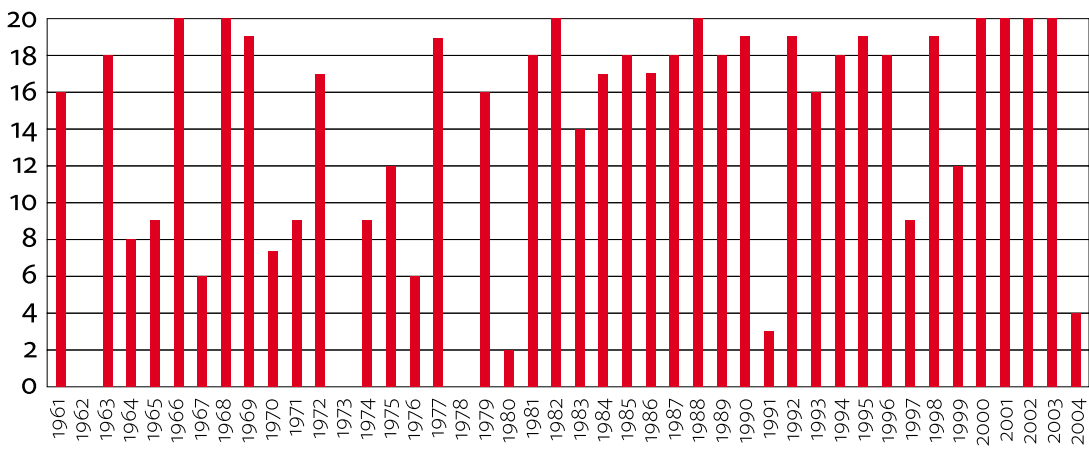

Figure 3 Number of stations with at least one extremely warm month

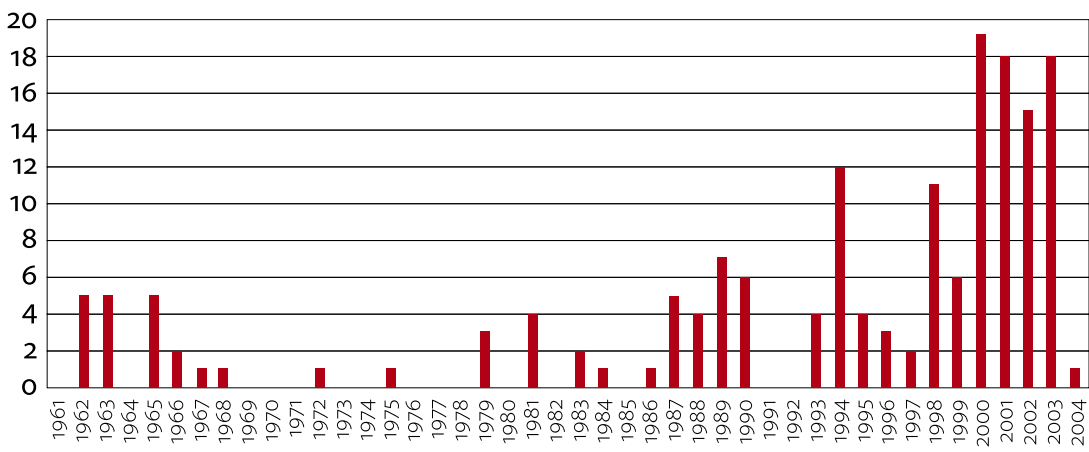

Figure 4 Number of stations with three and more extremely warm month circulation for air temperature variability in Bulgaria.

\section{Results and discussion}

\section{Spatial and temporal changes in extremely} monthly temperatures in Bulgaria during the period 1961-2004

The results of the research show that during the period 1961-2004 at least one extremely cold month have been observed in all 20 investigated stations in 1965, 1969, 1976, 1986, 1991, 1997, 1998 and 2003 (fig. 1). Number of extremely cold months decrease after 1990. Three and more extremely cold months are observed in less 10 meteorological stations. The years 1969, 1976, 1980, 1996 and 1997 make impression with three and more extremely cold months (fig. 2.).

By comparison between extremely cold and extremely warm months we can see that in the period 1961-2004 extremely warm months have been occurred more often (fig. 3). Most of investigated stations have three and more extremely warm months after 2000 (fig. 4). The increasing of extreme weather events in pointed out by many authors as a result of anthropogenic induced global warming. The results of present research show that there is increasing of frequency of extreme temperatures months (cold and warm) in Bulgaria after 1980 s.

Figure 5 shows number of extremely warm and extremely cold month for the year in the average series of Bulgaria for the period 1901-2000. Extremely warm months have been observed more often than extremely cold months. The results presented at fig. 5. allow as to conclude that extremely warm months after 1985 are not unusual. There are 5 extremely warm months in 1927, 4 - in 1947 and 1950 and 3 in many other years. But most important fact during last years is increasing of frequency of occurrence of extremely warm months after 1980. There is decreasing of extremely cold months during second part of investigated period.

Cluster analysis is applied in order to analyze spatial changes in the occurrence of extreme temperature months for investigated meteorological stations. By means of complete linkage and Euclidean distances we cluster stations that have similar features during the occurrence of extreme months. According occurrence of extremely cold months stations were divided into 3 clusters (1- North-West and North Bulgaria, 2- North-East, East and Central part of Bulgaria and 3-Southwest Bulgaria). The main factor for including stations into a given cluster is geographical situation and distance between stations. Application of cluster analysis for extremely warm months allows us to put Black Sea coast in separate cluster. Clusters for ex- 
tremely warm months are less spatially homogeneous in comparison to clusters for extremely cold months (fig. 6-7).

\section{Correlation between number of extremely cold and extremely warm month and NAO}

The NAO variability exerts a dominant influence on wintertime temperatures across much of the NH and it explains about onethird of the $\mathrm{NH}$ interannual surface temperature variance during winter (Hurrell, 2000).

Investigation of relationship between air temperature in Bulgaria and NAOI confirms the results of previous research (Nikolova, Noda, 2004). The correlation is negative and in most of cases is not statistically significant. Statistically significant coefficients are calculated for cold months in north part of Bulgaria.

\section{Correlation between extremely temperature months and $E A$}

The EA pattern exhibits very strong multidecadal variability in the 1950-2004 record (http://www.cpc.ncep.noaa.gov/data/teledoc/ea.shtml). Correlation analysis shows that EA pattern has influence mainly on occurrence of extremely warm months in Bulgaria. The correlation coefficients are between 0.35 and .52 and they are statistically significant. Good correlation between EA pattern and number of extremely warm months confirms that positive phase of EA occurring during 1977-2004 is associated with above-average surface temperatures in Europe. During the period 1981-2004 we have observed at least one extremely warm month in all station from the investigated region and there are three and more warm months in most of station after 1989.

\section{Conclusion}

The following conclusions can be made on the base of present research:

- Fluctuations of air temperature in Bulgaria are coinciding with global climate trends (for instance, increase in warm and decrease in cold extremes during the 1990s and in the beginning of present century).

- The years from 2000 to 2003 are the warmest in the investigated period.

- The number of extreme events increases during last years.

- According the features during the occurrence of extreme months station were divided into 3 (4) clusters, following direction $\mathrm{N}-\mathrm{S}$ or $\mathrm{W}-\mathrm{E}$.

- The main factor for including stations into a given cluster is a geographical situation and distance among stations.

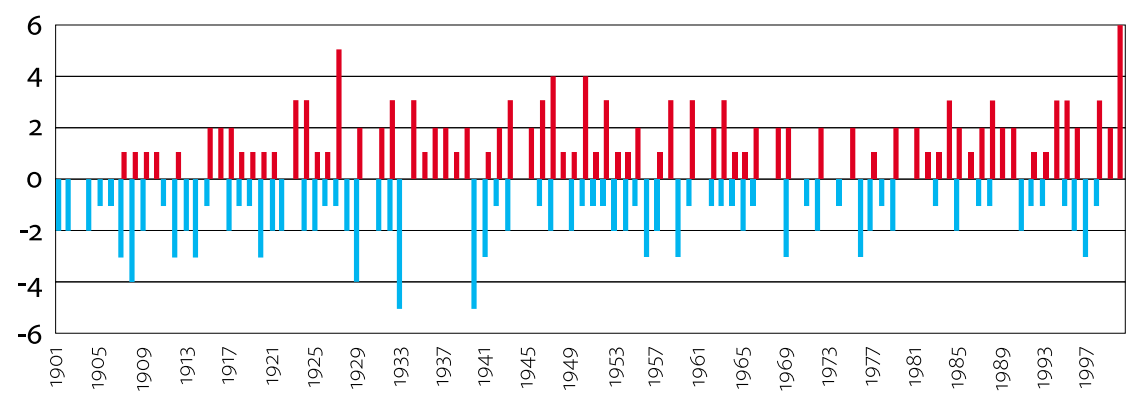

Figure 5 Number of extremely warm (positive values) and extremely cold (negative values) month for the year in the average series of Bulgaria

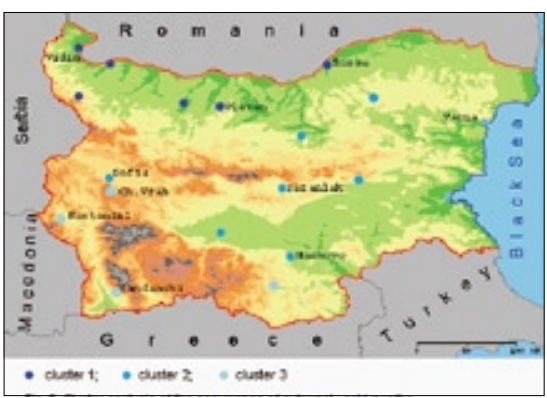

Figure 6 Cluster analysis of the occurance of extremely cold months over the territory of Bulgaria in the period 1961-2004

- The relation between temperature variations in Bulgaria and NAO is not clearly determined. Most important for occurrence of extremely warm months in EA pattern.

\section{Acknowledgements}

Authors would like to express their gratitude to Prof. R. Brazdil from Department of Geography, Faculty of Science, Masaryk University, Brno, Czech Republic for useful discussion.

\section{Reference}

Alexandrov, V., Schneider M., Koleva, E., Moisselin, J-M. 2004. Climate Variability and Change in Bulgaria during the 2oth Century. Theoretical and Applied Climatology 79, 133-149.

Barnston, A. G., and B. E. Livezey, (1987): Classification, seasonality, and persistence of low-frequency atmospheric circulation patterns. Mon. Wea. Rev, 115, $1083-1126$

Jones P. D, Jonsson T., Wheeler D. 1997. Extension to the North Atlantic Oscillation using early instrumental pressure observations from Gibraltar and SouthWest Iceland. International Journal of Climatology 17, 1433-1450.

Hurrell J. W. 200o. Climate: North Atlantic and Arctic Oscillation (NAO/AO).

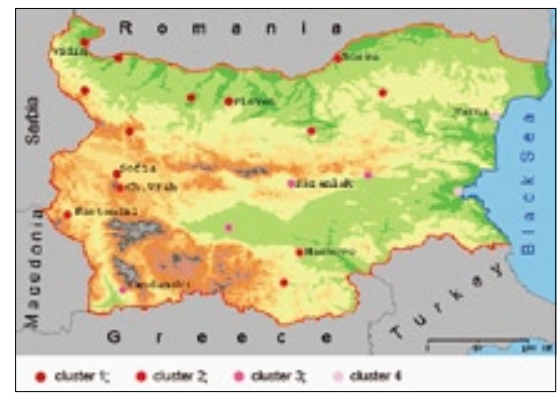

Figure 7 Cluster analysis of the occurance of extremely warm months over the territory of Bulgaria in the period 1961-2004

Encyclopedia of Atmospheric Sciences. Academic Press.

Mitchell, T. D., Hulme, M., New, M. 2002): Climate data for political areas. Area 34,109-112, http://www.cru.uea.ac.uk/ $\sim$ timm/papers/area-paper.pdf

Nikolova, N., Noda, A. 2004. The Variation of the Surface Air Temperature in Bulgaria under the Global Climate. Sofia University Year Book, Geography 96,

Osborn T., J. 2006. Recent variations in the winter North Atlantic Oscillation. Weather 61, 353-355.

Velev, St. 2003. Is climate of Sofia during 20 century has been changed. Study Geography, 4. (in Bulgarian)

Velev, St. 2002. Global climatic changes and climate of Bulgaria. Geography 21, 2., 4-9. (in Bulgarian)

Vekilska, B. 1973. Thermal characteristic of winter on Bulgarian Black Sea Coast. Sofia University Year Book, Geography 65 (in Bulgarian)

Tishkov, H. 1963. Temperature inversions in winter-time at Middle Predbalkan between Rocitsa and Belitsa Rivers. Bulletin of Institute of Geography 7.

Topliiski, D. 2002. Climatic Change in Bulgaria during the period 1901-1990. In Development and State of the Natural Environment. Ed. T. Krastev. Pp. 98106. (in Bulgarian) 